records a belief that views about life and death have changed over the years but most dramatically in the latter half of the twentieth century.

It is this change, combined with the increased ability of modern medicine to prolong life, that is given as the reason for the current preoccupation with issues surrounding death and dying. This then is the justification put forward for the publication of this volume. The book itself proclaims that it can offer no ready answers, but it is a useful collection of well-written articles which provides a good overview of the area for any reader, whether medical or not.

The book, though, can fairly be said to be primarily directed towards medical practitioners who at the current time and under current law, must most often make the decisions about life and death. Living wills now have legal status and so sometimes incompetent as well as competent patients can have a say. At present their decisions are limited in the main to treatments they will not have rather than those they may think they might like, certainly if those treatments threaten or terminate life. Occasionally the law steps in with guidance. The House of Lords, however, has made it clear that the law is unwilling to interfere with the decisions of doctors. This book discusses why doctors who put forward arguments for the merciful deliverance from suffering experienced by their patients are often accused of "playing god". Ironically, it is less often the case that they are accused of interfering with the will of a god, in whom fewer and fewer people are reported to believe, when they insist on keeping them alive.

JANE PRITCHARD Solicitor,

8 Dartmouth Road, Olney MK46 4BH, UK

\section{Report of the Working Party on Quality of Life and the Practice of Medicine}

Edited by Basil Mitchell and Michael Banner, Oxford, Ian Ramsey Centre, 1995, 68 pages $£^{3}$.

This report from the Ian Ramsey Centre is the outcome of a process begun in 1985 under which an interdisciplinary group, composed largely of Oxford practitioners and academics, met to discuss the concept of quality of life. It is aimed at health care professionals, and attempts to speak to those who have misgivings about the concept but who none the less find themselves unavoidably appealing to it in their work.

The report begins by laying out six actual cases (presumably suitably anonymised) which highlight questions the group wants to raise about the notion of quality of life. These include whether it is right to be concerned with quality of life at all; whether quality of life can be measured; if it can, by whom it is to be calculated; whose quality of life is to count; implications for resource allocation, and risks of quality of life assessments. The cases are clearly presented and thought-provoking, and would make useful discussion material for any group, whether composed of professionals or interested lay people.

The discussion of the issues raised in the cases that follows is admirably clear and succinct, and commendably condenses a considerable amount of thinking into a manageable length. In particular the editors are to be congratulated on avoiding a committeelike tone to their discussion, which at all times manages both to be interesting and to attain the journal's high standards of English accessible to any intelligent reader.

The report relies unashamedly on a principle-based approach to its discussion of the issues surrounding the cases, a strategy that will delight or appal according to the reader's personal view of this model of ethics. This exclusively principlist methodology is neither remarked on nor defended by the editors, which perhaps reflects the report's twelve-year gestation period. Begun at a time when the principle-based method held almost undisputed sway in health care ethics, the report now emerges into a world in which the approach is but one among many, and which needs to be defended against alternative methodologies.

The report considers three main principles - non-maleficence, autonomy and beneficence - to which it adds further principles in a supporting role, viz fairness, sanctity of life, and veracity and confidentiality. Not unconventionally, these are viewed as being arranged hierarchically, with the duty of non-maleficence trumping patient autonomy, which is in turn regarded as of greater moral weight than the duty of beneficence. This derivation of the hierarchy of the principles from the dictum primum non nocere should ensure a favourable reception for the report at least among its medical audience.

Readers from a background in academic philosophy are likely to be slightly less entranced by the report, not least by virtue of its use of hackneyed illustrations. The example of a strong swimmer passing a drowning man in an otherwise deserted swimming pool may pose the question of supererogatory beneficence clearly, but it flirts with the boundaries of cliché. It is also regrettable that the number of references to medical writings is not matched by ones to other philosophical discussions in the area, which means that the reader coming anew to the report would be at a loss to follow up many of the conceptual and ethical issues raised.

The report is extremely useful in bringing together in one place an example of the principle-based approach as applied to quality of life judgments, and thus making a summation of a vast body of literature available to those who might not otherwise have the opportunity to access it. As an excellent survey of thinking on the subject, its value is somewhat lessened not only by the incompleteness of its references, but also by the twelve years that have elapsed between its inception and publication, which means that in places (for instance on the issue of advance directives) it has been overtaken by legal and ethical thinking, but this should not take too much away from what is a valuable review essay of an important area.

RUPERT JARVIS Ripon College, Cuddesdon, Oxford

\section{Human Lives: Critical}

\section{Essays on \\ Consequentialist Bioethics}

Edited by David S Oderberg and
Jacqueline A Laing, London,
Macmillan, 1997, 244 pages, $£ 40$.

Consequentialism has had a powerful impact on bioethics: an impact some believe is out of all proportion to its intellectual merits. This book brings together a group of anti-consequentialist essays, with the aim of correcting 